\title{
Effect of atmospheric stability on the estimation of wind power potential
}

\author{
M. M. Ichenial ${ }^{1}$, A. El Hajjaji ${ }^{1}$, and A. Khamlichi ${ }^{2}$ \\ ${ }^{1}$ Department of Physics, Faculty of Sciences at Tetouan, 93030, Morocco \\ ${ }^{2}$ Department TITM, National School of Applied Sciences, Tetouan 93030, Morocco
}

\begin{abstract}
Analyzing the impact of atmospheric stability on vertical wind profile enables to assess the available wind resource in order to determine optimal locations for wind turbines. Different methods have been proposed to study the degree of stability of the atmosphere. These include the Richardson number, the profile method and the Monin-Obukhov length. Focus is here on the stability issue and its influence on the wind shear coefficient which plays an important role in processing experimental data with regards to the atmospheric surface-layer turbulence. Data collected from the Cabauw meteorological mast were analyzed in order to determine the characteristics of the wind resource at that location and to estimate the wind resource for power generation as affected by stability.
\end{abstract}

\section{Introduction}

Wind energy has evolved tremendously during the last few decades. Most of wind projects are developed based on the mean wind speed at the hub height of the turbine without any consideration of atmospheric stability effect. However, significant dependence of wind resource on this stability issue has been recognized $[1,2]$. Stability is linked to the influence of the thermal effects. Unstable stratification occurs when there is a lot of surface heating. The warm air rises and the result is a thick boundary layer with heavy turbulence in the air. If the adiabatic cooling effect causes the rising air to become colder than its surroundings, its vertical motion will be suppressed. This is called a stable stratification. It occurs at cold nights when the ground surface is cold. In this situation, the movement of the air is dominated by friction with the earth surface and the increase in mean wind speed with height is large. In a neutral atmosphere, adiabatic cooling of the air as it rises is such that it remains in thermal equilibrium with its surroundings. This is often the case with strong winds. For wind energy utilization, neutral stability is the most desirable situation [3].

The mean wind speed constitutes only a rough measure of the wind resource and does not provide a high accurate estimate of energy production. The wind resource must also be characterized by the variations in speed and direction, as well as air density, in time and space [4]. Sufficient temporal and spatial dimensions of wind resource assessment are required for suitable wind farm design. Focus is here on the stability issue as it affects the wind shear coefficient for a particular site where stability is found to be significant. Three stability criteria are applied and the modified wind shear coefficients are obtained and used to evaluate the estimated energy production for that site.

\section{Stability of atmospheric boundary layer}

The atmospheric boundary layer is the lowest part of the atmosphere and its characteristics are directly influenced by contact with earth's surface. Here, physical quantities such as velocity, temperature, and relative humidity can change rapidly in space and time. An important parameter in the characterization of the wind resource is the variation of horizontal wind speed with height above the ground. One would expect the horizontal wind speed to be zero at the earth's surface and to increase with height in the atmospheric boundary layer. This variation of wind speed with elevation is called the vertical profile of the wind speed or vertical wind shear. The variation of 'instantaneous' profiles is related via the similarity theory of boundary layers. On the other hand, the changes in long- term averages as a function of height are related to the statistics of occurrence of various influencing factors, such as atmospheric stability and surface roughness.

A particularly important characteristic of the atmosphere is its stability - the tendency to resist vertical motion or to suppress existing turbulence. The stability of the atmospheric boundary layer is a determining factor for the wind speed gradient or wind shear that are experienced in the first few hundred meters above the ground. Numerous classification systems have been developed to define the atmospheric stability. In this study we use the flowing methods: 
- Monin- Obukhov similarity theory [5];

- Richardson Numbers [6-9];

- Profile Methods [10,11].

These methods are applied in the following to a site which is located near the Cabauw village in the center of Netherlands for which wind data is available.

This location was chosen because its topography is very suitable for boundary layer measurements. The surroundings are flat within a radius of at least $20 \mathrm{~km}$.

\section{Wind data from the Cabauw site area}

The Cabauw tower is located at the geodesic coordinates $51^{\circ} 58^{\prime} 16^{\prime \prime} \mathrm{N}$ and $04^{\circ} 55^{\prime} 36^{\prime \prime} \mathrm{E}$. The foot of the tower is at $0.5 \mathrm{~m}$ below mean sea level. The distance to the sea is about $45 \mathrm{~km}$. The weather in the area is characterized by a moderate maritime climate, with a prevailing westerly circulation. Meteorological data for this site are from Rotterdam Airport: KNMI meteorological station. These data are related to Greenwich Mean Time. As identified in 1987, the meteorological roughness height of the site was fixed to the value $0.15 \mathrm{~cm}$.

Measurements are available as 10 min averages over several years. Here data of the years 2011, 2012 and 2013 are used. Wind velocity and direction are measured at 10 , 20, 40, 80, 140 and 200m altitude. The considered data refer here to wind velocity at the usual observation height of $10 \mathrm{~m}$ and at $80 \mathrm{~m}$ hub height. Wind shear will be presented for this height range as well as the range 40$140 \mathrm{~m}$ which corresponds to a common rotor of height between 40 and $120 \mathrm{~m}$.

During the three years (2011-2013) period, annual mean values of wind speed, turbulence intensity, wind power and total wind energy were as follows: $7.2 \mathrm{~m} / \mathrm{s}$, $14.3 \%, 110.25 \mathrm{~W} / \mathrm{m}^{2}, 72.91 \mathrm{~kW} / \mathrm{m}^{2}$ respectively.

\subsection{Analysis of stability}

The measurements from the Cabauw tower are preprocessed before analyzing stability according to the three methods mentioned above. The results are filtered with a stationary filter that excludes the values measured when the mean conditions of air are changed rapidly and for which the airflow cannot be considered as a stationary field [12].

The pie chart of the stability parameter is displayed in figure1. One can see from this figure that except the Profile Method 1, the other methods used to estimate the atmospheric stability give closer results.

A continuous display of the stability distribution will enable to have a better idea about the atmospheric stability of the chosen site. A comparison is conducted in the following at multiple levels [13]:

- Atmospheric stability distribution per hour of the day;

- Atmospheric stability distribution per month;

- Atmospheric stability distribution per wind direction.

Wind data acquired during the period 2011-1013 for Cabauw was processed form the stability viewpoint.

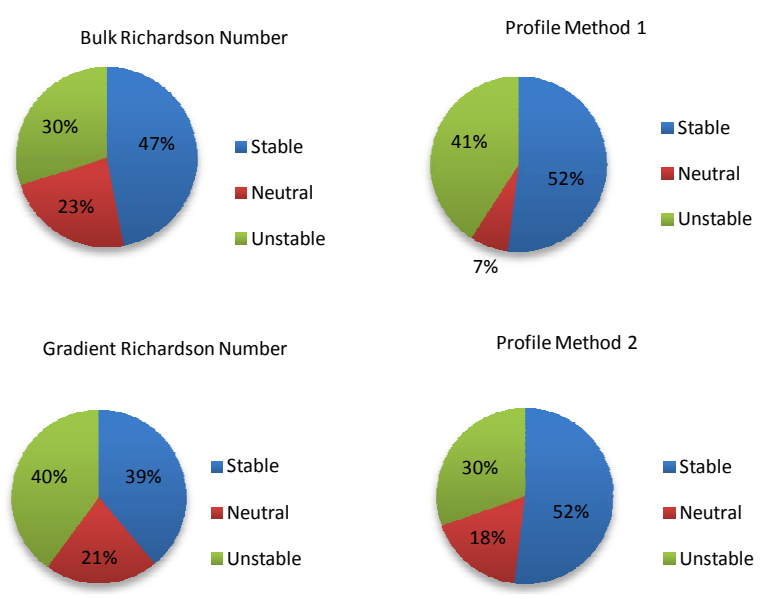

Fig. 1. Comparison of atmospheric stability distribution divided into three classes.

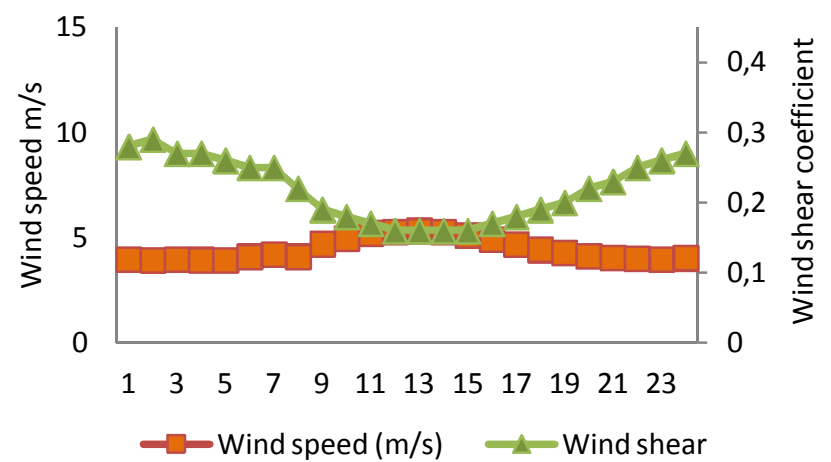

Fig. 2. Variation per hour of the day by stability class of 10 -min annual mean wind speed and wind shear observed.

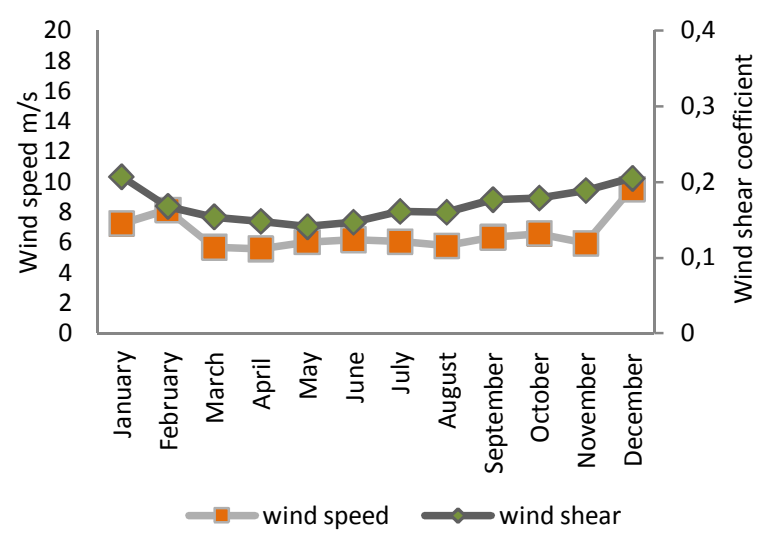

Fig. 3. Monthly variation by stability class of 10 -min annual mean wind speed and wind shear coefficient observed

Figure 2 gives variation per hour of the day by stability class of 10-min annual mean wind speed and WSC observed.

Figure 3 gives monthly variation by stability class of 10min annual mean wind speed and wind shear coefficient observed. 


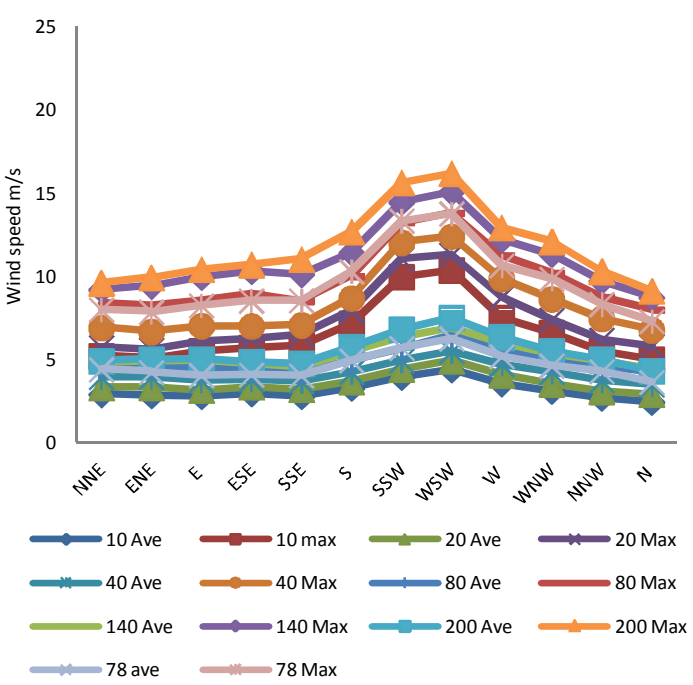

Fig. 4. Variation per wind direction by stability class of 10 -min annual mean wind speed and wind shear coefficient observed.

Figure 4 gives variation per wind direction by stability class of 10-min annual mean wind speed and wind shear coefficient observed.

Figure 2 shows that according to the Bulk Richardson Number, the atmospheric stability is mainly very stable with almost no unstable and very unstable condition during the night. Comparing this with estimation of the Profile Method 2, the very stable conditions occur less frequently and near neutral and stable conditions occur more frequently. The Profile Method 1 describes the atmosphere with almost only extreme conditions and therefore compares badly with the Bulk Richardson Number method and Profile Method 2.

Figure 3 shows that according to Bulk Richardson Number and Profile Method 2 small fluctuations between each month can be observed. With in the months of March, April, May and June a peak of around 30\% of very unstable conditions is observed. The Profile Method 1 and Gradient Richardson Number give a much higher estimation of the very unstable conditions, with the peak occurring in the same months. This indicates seasonal influences on the atmosphere stability, which are visible in the distribution of the unstable and very unstable conditions.

Figure 4 shows that the Profile Method 1 gives a higher frequency of occurrence for very unstable conditions and lower frequency of occurrence for unstable and neutral conditions compared to the Bulk Richardson Number, Gradient Richardson Number and Profile Method 2.

\subsection{Effect on power production}

The effect of atmospheric stability as determined for the wind data from the Cabauw site has been analyzed for the reference wind turbine: Gamesa G80-2.0MW.

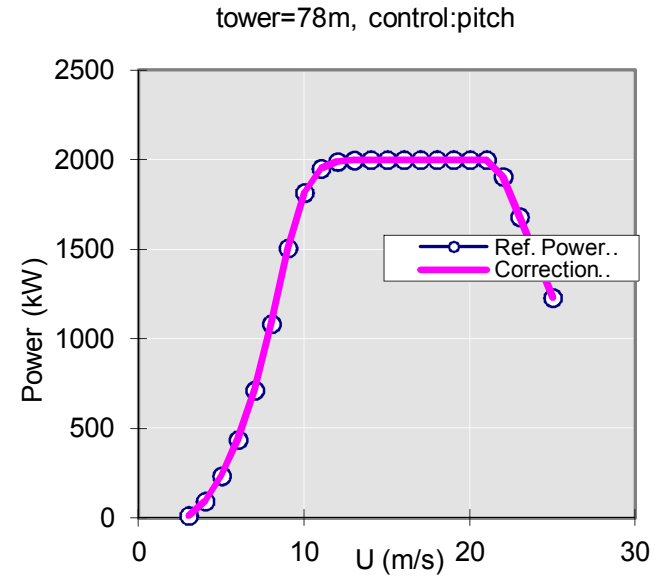

Fig. 5. Power as function of the wind speed for the wind turbine, Gamesa G80-2.0MW.

Figure 5 gives the Gamesa G80-2.0MW power characteristic.

Processed results from the Cabauw area have shown that the shear exponent in the lower atmosphere boundary layer $(<200 \mathrm{~m})$ in day time varies in the interval 0.1 to 0.2 . This corresponds to a wind velocity ratio $\mathrm{U}_{80} / \mathrm{U}_{10}$ which varies between 1.2 to 1.5 .

At night the situation is quite different as the shear exponent has a much wider range with values up to 0.8 , but more usually between 0.2 and 0.6 showing that the site indeed was suitable to study the effect of atmospheric stability on wind potential.

Figure 6 gives the estimated energy as function of wind direction.

Figure 7 gives the estimated wind turbine energy production per month.

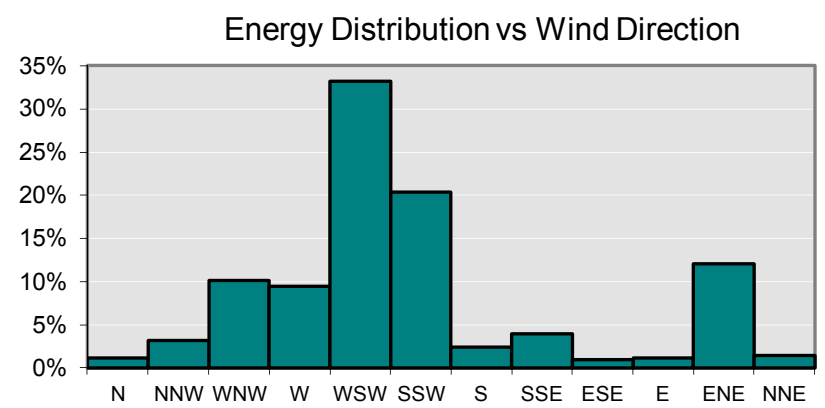

Fig. 6. Energy distribution as function of wind direction for the Gamesa G80-2.0MW in Cabauw site

Taking into account atmospheric stability criteria, figure 7 shows that wind turbine energy production is largely affected by the wind shear coefficient which results in form the state of stability. The wind shear coefficient determines the vertical wind speed distribution over the rotor plane. The predicted wind energy production is like this different from that one associated to a constant overage wind shear coefficient. 


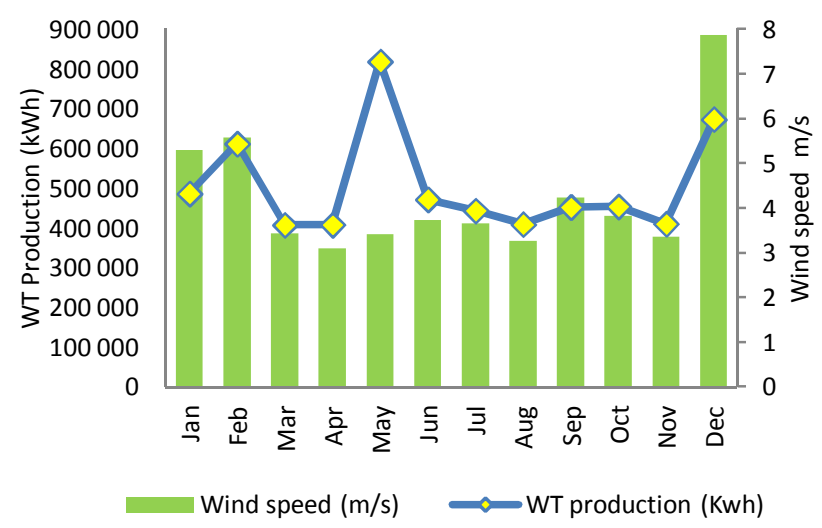

Fig. 7. Variation of the wind turbine energy production per month for the Gamesa G80-2.0MW in Cabauw site

\section{Conclusions}

Atmospheric stability is a key issue for estimating the wind resource that is available for a given site. The stability state modifies the wind shear coefficient and energy as it can be captured by a standard wind turbine. In this work, various stability criteria have been applied to measurement data for a particular site. The obtained results in terms of energy production have shown that stability can yield significant variations in comparison with the constant profile method based on the average wind shear coefficient.

\section{References}

1. A. Sathe, J. Mann, T. Barlas, W.A.A.M. Bierbooms, G.J.W. Bussel, Influence of atmospheric stability on wind turbine loads, Wind Energy, 16, 1013-1032 (2013)

2. B. Lange, S. Larsen, J. Højstrup, R. Barthelmie Importance of thermal effects and sea surface roughness for offshore wind resource assessment, Journal of Wind Engineering and Industrial Aerodynamics, 92, 959-88 ( 2004)

3. J. Rohatgi, An Analysis of the Influence of Atmospheric Stability on Vertical Wind Profiles Its Influence on Wind Energy and Wind Turbines, Wind Eng. 319-332 (1996)

4. H. Erich, Wind Turbines: Fundamentals, Technologies, Application, Economics $2^{\text {nd }}$ edition, (Springer, Germany, 2006)

5. T. Foken, 50 Years of the Monin -Obukhov Smilarity Theory, Boundary-Layer Meteorology, 119, 431-44 (2006)

6. A. Sathe, W. Bierbooms, Influence of Different Wind Profiles due to Varying Atmospheric Stability on the Fatigue Life of Wind Turbines, (The Science of Making Torque from Wind, IOP Publishing, 2007)

7. B. Lange, S. Larsen, J. Hojstrup, R. Barthelmie, The influence of thermal effects on the Wind Speed Profile of the Coastal Marine Boundary Layer. Boundary-Layer Meteorology, 112, 587-617, (2004)
8. M. Mohan, T.A. Siddiqui, Analysis of various schemes for the estimation of atmospheric stability classification, Atmospheric Environment, 32, 33753781 (1998)

9. A. Grachev, C. Fairall, Dependence of the MoninObukhov Stability Parameter on the Bulk Richardson Number Over the Ocean, Journal of Applied Meteorology, 36, 406-415 (1996)

10. A. A. M. Holtslag. Estimates of diabatic wind speed profiles from near-surface weather observations, Boundary-Layer Meteorology, 29, 225-250 (1984)

11. M. Motta, R. J. Barthelmie, P. Volund, The influence of non-logarithmic wind speed profiles on potential power output at Danish offshore sites, Wind Energy, 8, 219-236 (2005)

12. D.A. Spera, Wind Turbine Technology: Fundamental Concepts of Wind Turbine Engineering, second ed., (ASME Press, New York, 2009)

13. J.J.W. Hutschemaekerrs, comparison of classification systems to define atmospheric stability and their impact on wind turbine design, (Delft, 2014) 